\title{
A Critical Analysis of Bollywood Actor Aamir Khan's Selected Movies
}

\author{
Afaq Ahmad* \\ Research Scholar, Department of Mass Communication, Aligarh Muslim University, Aligarh-202 002, (Uttar \\ Pradesh), India
}

*Corresponding Author: Afaq Ahmad, Research Scholar, Department of Mass Communication, Aligarh Muslim University, Aligarh-202 002, (Uttar Pradesh), India

\begin{abstract}
Movies are rollercoaster voyage having stunning persuasion and exhortation to entertain the viewers. Movies leave invigorating and rejuvenating impact on cinemagoers' minds as they can be retrieved and replayed time and again. As far as Bollywood film actor Aamir Khan's movies is concerned, it can be an essential ingredient and catalyst to bring about a methodical social change. In other words, Aamir Khan's movies seem to be a testament to societal reform in the country. Very few studies have been undertaken on Aamir Khan's movies, and on the inescapable messages contained in his movies. The key objective of this paper is to acknowledge the different roles played by Aamir Khan in his movies and analyse the treatment given to the contents in these selected movies. Based on the study of three selected films of Aamir Khan, the researcher made an attempt to diagnose the socio cultural elements scattered in these movies. These movies were willingly selected as AndazApnaApna - a comedy movie, Raja Hindustani - a romantic movie, and Ghulam - a playback singer movie with the intention to go through the multiple aspects in corporated in these movies. The researcher seeks to explore the multifaceted, multidimensional and multi skilled narrative about Aamir Khan by highlighting the stories of various aspects of the society in his films. The outcome of the research study reveals that entertaining, appealing, and captivating features are vigorously portrayed in these movies. Further, the study shows that the beguile, humorous and witty aspects found prominence encompassing dissimilar and divergent communication threads in these three selected movies under study.
\end{abstract}

Keywords: Hindi Movies, Aamir Khan, Critical Analysis, Multidimensional Films, Comedy, Romance, Playback Singer.

\section{INTRODUCTION}

The way Aamir Khan portrays various characters in his movies make him a perfect actor of adaptable characteristics. He is humble enough to boost his prospects with talent and a lot of hard work.

Aamir Khan started his career in films with a runaway success called Qayamat Se QayamatTak, a film directed by his cousin, Mansoor Khan, which turned out to be a blockbuster of 1988 and set a new trend in Indian cinema. And, this dramatic turnaround has hardly been a matter of chance. He had obviously learnt from his past mistakes and ensured that every project he lent his name to had something special to offer (Vijayakar, 2012).

First, there was 'Dil Hai KeMaantaNahin'(1991), Mahesh Bhatt's breezy remake of the Raj KapoorNargis road movie, 'ChoriChori.' Then, he brought immense conviction to the role of a young and carefree high school boy in Mansoor Khan's 'Jo JeetaWohiSikander'(1993). Aamir displayed a natural flair for comedy with 'Hum Hain RahiPyaarKe'(1993) and RajkumarSantoshi's slapstick 'AndazApnaApna'(1994). Significantly, by this time he had also cut his workload down to not more than two or three films in a year. His transition from teen idol to a mature and sensitive actor came about with the Indianised adaptation of 'Kramer vs. Kramer' in 'Akele Hum Akele Tum'(1995). Aamir, who had already become a father by then, claimed his personal experiences with son Junaid went a long way in helping him play the part of a 'single' father. 'Rangeela' and 'Raja Hindustani'(1996) had Aamir make another studious change to his image, playing to the gallery with over-the-top performances and characters the front-bencher could easily identify with. He pulled out another surprise from his hat essaying the role of a no-nonsense, upright police officer who busts a major arms racket on the Pakistan border in 'Sarfarosh' (Verma, 2012). 
An important aspect of Aamir's success is the fact that he has thrived on carefully chosen characters in films, but has never worked with the likes of Mani Ratnam, SubhashGhai, or even David Dhawan. Instead, he has backed unknown names such as AshutoshGowarikar ('Baazi') and John Matthew Mathan ('Sarfarosh') and even a flop filmmaker like Vikram Bhatt.

Seasoned artiste now, Aamir is slowly turning to production. His first film as a producer is a period film entitled Lagaan, which turned out to be a super block buster and was also nominated for the Oscars. His next release was Mangal Pandey:The Rising in which he played the title role with a sense of devotion.

\section{AAMIr Khan: Mister Perfectionist}

Undoubtedly, Aamir Khan is famous for concentrating on one film at a time, refusing scenarios that do not have any content, involving himself in his roles totally. And, this attitude normally speaks in his favour. One more thing, when the researcher watches him in most of his films-the ones the researcher has seen at least-there he is simple but aggressive, virile, enthusiastic, impassionate, revolutionary and histrionic. And, you cannot escape him; he has got the main role.

Aamir Khan is hard-working, dedicated and he always tackles serious issues. He has done good films, he is not interested in money for the sake of money; he does not do masala and all that cheesy sentimentality, that gaudiness. One can say that he has grown into a respectable actor and director. Being choosy about what one does in Bollywood is so rare that it has to be noted. He is modern, reachable, he believes in himself and he takes risks. He is a versatile, clever little man who has not only acted and directed but also sang as a playback singer (Ghulam and Mangal Pandey) and produced his films - Rang De Basanti and TaareZameen Par.

DilChahta Haigot innumerable publicity among youths and it get remembered a trendsetter movie in Indian film making. Whereas, Ishqand AndazApnaApna not only has comic moments and romantic interludes, but it also shows problems that exist in the society that the viewer inhabits. And, through his comedian skills, he could safely grace any film without necessarily lording it all that much.

Aamir is a perfectionist; we read this all the time. We can easily prove it through his movies, bathed in different colours and shades. He is a challenging personality who can adopt the role of a romantic hero in Rangeela(as Munna), Raja Hindustani, Mann (as Karan Dev Singh), and Fanaa (as Rehan Khan). Moreover, he can adjust a role in negative shades in 1947 Earth (as Dil Nawaz, the ice-candy man) and Fanaa. On the contrary, Lagaan(as Bhura) and MangalPandey depict him in a patriotic and revolutionary characteristic. We can also watch him on the celluloid as an honest and dedicated Police Officer in the movie Sarfarosh(as Ajay Singh Rathore).

He is a real professional, interested in the important issues, and probably sees his career as a mission. His culture, his country can benefit from an intelligent and committed activist like him. He has innovative ideas and the zest to address the problems he feels deeply about, and uses cinema as means to do that. Rakesh Mehra'sRang de Basanti is a good example. It undoubtedly tackles real problems that plague modern India, and it does so in an original way. That Aamir Khan is part of that significant way of joining an understanding of the past to a consciousness of the ills of the present, that's a testimony to the fact that he definitely chooses his films well. His involvement as producer in Lagaan is also interesting. In his movies he is clearly addressing some of India's social problems (viz., 3 Idiots, Lagaan, TaareZameen Par etc.), but he (as a producer) enables the cinema to be reckoned as a political weapon. In Faana, by KunalKohli, he puts on a very good show too. He is first that bratty tourist guide who half-heartedly falls for the innocent visually challenged villager girl, and then he's that hardened nationalist or ideologist who must deal with the moral problems of being also a father and a husband. He is sometimes betrayed by the film's contortions, but on the whole, he is very believable, and his performance is great.

Really speaking, Aamir Khan is the latest incarnation as India's most respected and versatile actor. Gone is Aamir Khan, the hipster in a tight-fitting silk suit, outrageous tie and boyish close-crop whom millions watched strides the red carpet outside a score of premieres. In his place, meet Aamir Khan, Jesus Christ Superstar.

If you have seen Aamir in AndazApnaApna (1994), you would know what makes him such a great actor. This RajkumarSantoshi film, starring Salman Khan, RaveenaTandon and Karisma Kapoor was one of the funniest films of the year. Aamir's delicious wickedness and 'I am so 
smart' sort of act would keep you in splits throughout the film. Unfortunately, the film did not do well. However, this flop did not hamper Aamir'scareer in any manner. Whether it was playing the local city boy in Rangeela (1995), a taxi driver in Raja Hindustani (1996) or the flamboyant youngster in DilChahta Hai (2001), Aamir did all of that in style(Bamzai, 2010).

Having to explain over and over again why he does so few films, Aamir tried again. "As creative people, we're always outputting things. What's important is to input things. I enjoy meeting people, reading up, seeing places. I need to take in inputs. It takes me time to prepare for a role."

Aamir further explains about selecting a particular script for making a film and speaks like a true actor, "If it doesn't do justice to the original, it will be nothing short of a crime to make it. The world should see what is in our culture and mythology. It should be given its due. Whoever makes it and whenever it's made, it had better be made well, immaterial of whether I'm a part of it or not."

Most importantly, he vied to be in control was becoming apparent from complaining directors who were upset that they had to, apart from narrating the entire script to the actor, deal with his various "suggestions" while shooting.

\subsection{Objectives of the Study}

- To verify the assumption that Aamir Khan's movies have diverse contents and multifaceted characteristics;

- To study the depiction of Aamir Khan's movies in different perspectives;

- To examine the differences in the motifs and themesin the movies under study;

- To identify the impact and consequences of Aamir Khan's movies for sociocultural transformation of the society.

\subsection{Hypothesis}

- AndazApnaApna, Raja Hindustani, and Ghulam encompassesdiversified characteristicsin the contents of these movies.

- AndazApnaApnais basically a comedy film which seems to be againstAamir Khan's persona as being a serious actor.

- Aamir Khan played a romantic role in Raja Hindustani to evoke emotive sense and ooze catharsiswhereas Ghulam fills the feeling of a roguish or unscrupulous boy in his characterwhich appears to be against the serious acting of Aamir Khan on silver screen.

\section{RESEARCH METHODOLOGY}

The methodology espoused in the study is the Content Analysis of the important Hindi films of Aamir Khan having different stories and screenplay. To fulfil it, three films of Aamir Khan were willingly picked up from a number of movies keeping in mind the heterogeneous stories and treatment with the contents. The criterion behind the selection of the films has been their heterogeneity of stories and screenplay.

In order to conduct comprehensive and rigorous analysis of the movies under review, the most potent and virtual method was to watch the movies and distinguish the diversified contents and screenplay of his movies. After having a qualitative assessment of his films, the findings have been extracted to draw relevant conclusions and suggestions.

\section{A Critical Analysis of the Three Selected Movies of Aamir KHaN}

\subsection{AndazApnaApna: Genre - Comedy}

\subsubsection{Film Review}

The movie was released on November 4, 1994. Though, the film was not gained much success at the box office but will be remembered as a cult film of Bollywood over the years. The glossary of the movie had become a part of daily language that time. 
AndazApnaApna is an excellent entertainer. For a comedy film, it could not have been better. The performances, direction, dialogues are all first class. Amar (Aamir Khan) and Prem (Salman Khan) are two never-do-wells from Mumbai and Bhopal respectively who dream of becoming rich by marrying a millionaire's daughter Raveena(RaveenaTandon). One has a habit of saying 'aila!' and the other has a habit of saying 'ooiimaa!' They meet on a bus and discover that they are both out to win the heiress. Aamir and Salman try all their feasible best to outwit each other and woo Raveena. Moreover, each of them employs multiple manoeuvres to abolish his contender, all of which fail ludicrously. In the end, Amar and Prem agree to join forces, insinuate themselves into the heiress' household, and there compete for Raveena's love. Amar starts infuriating Raveena with trivial things. In the end, Raveena, fed up with him, hits him with a $\log$ of wood. Amar pretends to have become unconscious. He is taken into Raveena's stately home, where he is followed by Prem, professing to be a doctor. After some skirmishing for Raveena's concentration, Prem finds himself progressively enchanted to Karisma (Karisma Kapoor), Raveena's personal assistant. What Amar and Prem don't know is that Karisma is the real heiress. She switched places with her secretary in an attempt to find a man who would fall in love with her just for him, not for her affluence and prosperity.

Amar and Prem then manufacture an idiotic conspiracy to win the conviction and faith of the heiress's father Ram Gopal Bajaj (PareshRawal) by first abducting and then rescuing him. But they do not know that the father's wicked twin TejaaliasShyam Gopal Bajaj(PareshRawal) has plans to kidnap him too, and start living as him. So, Teja, Amar and Prem deploy their people to kidnap him. But the diabolical twin's men take him by supplying the men sent by Amar and Prem unconscious. Amar and Prem then decide that they will really have to rescue him.

But to make things even amateurish, shoddy and chucklesome, Teja himself has an opponent, Crime Master Gogo (Shakti Kapoor), who then enters into the scene and hatches a nefarious and sinister plot. He takes everyone captive, including Raveena, Karishma, Ram Gopal Bajaj, Teja and his companion Robert (VijuKhote) and Bhalla (Shehzad Khan) to steal the costly diamonds that belong to the rich Ram Gopal Bajaj. Amar and Prem go to rescue them all. Comic frivolity evolves and ultimately the villains are apprehended by the Police Inspector (TinkuTalsania) (Planet Bollywood, n.d.).

\subsection{Raja Hindustani: Genre - Romantic}

\subsubsection{Film Review}

The film was released on 15 November 1996. Following the trend of the 90's with the biggest hit of the year being a movie with little violence and great music, Raja Hindustani, comes as Aamir Khan's biggest hit of this year and Karisma Kapoor's ride into the most successful actress of the year. The songs became exceptionally popular, especially Pardesi, Pardesi. To my mind, the songs of the movie are the only reason the film became such a huge blockbuster in that the songs seem to be hypnotic and screenplay appears to be fetching and appealing.

Two people from conflicting socio-economic milieu fall in love and get married against the consent of the girl's family members. The girl's family then hatches a plot to construct a rift between the couple by exploiting the boy's anxious, envious and peevish nature.

Plutocratic and affluent Mr. Sehgal (Suresh Oberoi) lives with his daughter, Aarti (Karisma Kapoor), and her stepmother Shalini (ArchanaPuran Singh) in a sumptuous and luxurious home. Aarti wants to go for a holiday to a small hill station named Palankhet where her parents had met for the first time. Once there, she meets with taxi-driver Raja Hindustani (Aamir Khan), and after a short span of time, both fall in love with each other, and get married without Mr. Sehgal's wishes and benediction. Finally, Mr. Sehgal forgives his daughter, and invites both newly married couples to his palatial home, not knowing that his wife, her brother, Swaraj (PramodMoutho), and her nephew Jai (MohnishBehl) have stitched plansfor him and his daughter that will change their lives forever. Resultantly, the couple eventually split. After some time, Mr. Sehgal forgives his daughter and visits her in Palankhet. While there, he gives his daughter and son-in-law a new house. Raja declines to live in the house because he does not see it as a gift, but rather as a charity since he belongs from an impoverished background. Shalini, her brother, Swaraj (PramodMoutho), and her nephew Jai (MohnishBehl) seek to exploit this dispute to churn their vested interest and petty goals to grab Mr. Sehgal's property. 
Under the pretence of a birthday party, they bring Raja and Aarti to Mumbai and develop situations and events that cause Aarti and Raja to separate.

Aarti realizes that she is pregnant, but, due to health problems, the doctor advises her not to travel. Instead, her stepmother is asked to go to Palankhet to inform Raja about his would be child and to persuade him to come to Mumbai. However, Aarti's stepmother tells Raja that Aarti wants to divorce him. Raja refuses. After some time, Raja learns that Aarti has had a new born child and is under the impression that she intends to keep him away from the child. Fearing that he will never be allowed to see his baby, he chooses to abduct the child. Shattered and distressed, Aarti goes to see Raja and begs him to let her have their child back. Finally, the chicanery, lies and deceit of Aarti's stepmother are busted, and Aarti and Raja reunite (Mukherjee, 2017).

The movie appears to be a remake of Jab JabPhoolKhile or Akele Hum Akele Tum and it ends up as an uneasy mix of both. The movie got the Filmfare Award for Best Film, including Filmfare Best Actor Award to Aamir Khanand Filmfare Best Actress Award to Karisma Kapoor for their sterling performances.

\subsection{Ghulam Genre - Playback Singer}

\subsubsection{Film Review}

The film was released on 19 June 1998. Ghulam means a slave. Sidharth (Aamir Khan) is a nonprofessional boxer who does not work, preferring to loaf about with friends. His older brother Jai (Rajit Kapoor) works with a gang lord who rules the neighbouring areas of his locality, frightening merchants and demanding protection money. As a child, Sidharth idolized his father, an erstwhile freedom fighter, whom he saw committing suicide in guilt after a visit from an old acquaintance. Sidharth meets a girl, Alisha (Rani Mukerji), who rides with a motorcycle gang, and Hari, a social worker. The film tells the story of Sidharth's romance with Alisha and his reformation.

Once, a movie with Aamir Khan, Deepak Tijori, and a fairly new actress (Ayesha Jhulka) and music by Jatin-Lalit released. The result: Jo JeetaWohiSikandar. Likewise, the same pair of actors and music director combine with Ranee Mukherjee to come up with Ghulam. A song even resembles the fabulous "PelhaNasha", but the movie doesn't resemble Jo JeetaWohiSikandar(JJWS), not even a little bit.

Violence, roughness and rampage is the name of this movie, with a short love story twisted somewhere in the middle. Siddharth (Aamir Khan) is a Mumbai tapori(lumpen), an amateur boxing champion. His brother, Jai, makes money through a former boxing champion who now rules the community by terrifying people and stealing money from innocent merchants. Siddharth saw his father's death when he was a child; this mentally affected him throughout his life. His father's words remained with him, though he had only been with his father for short period. Siddharth meets a young woman, Ayesha (Ranee Mukherjee) who rides with a motorcycle gang and Charlie (Deepak Tijori). This is a flavour for some comedy and a brilliant scene in which Siddharth is running towards a train and as the train is only a few feet away he jumps out of the way. Siddharth and Ayesha meet for the first time and fall in love, and the typical love story follows. Siddharth meets another person who reminds him of his father, Hari. He learns a bit more from this man of wisdom whichencourages him to embracetruth. How he does this and how the message of Hari and his father is carried out is beingobserved in the movie.

Overall, the movie bores at times and excites some times. Ranee Mukherjee does a good job, and her acting has improved dramatically since her debut in Raja Ki AayegiBaarat. All the other actors perform brilliantly, but the movie doesn't come to the actor's standards. The songs are perfect for the movie, even Aamir Khan's "Aati Kya Khandala" works quintessentially with the movie. The one thing that seems to be lacking in this movie is direction. The use of a better director would have created a better movie. Rani Mukerji became known as the "Khandala Girl" after the hit song "Aati Kya Khandala” (Bollywood Hungama, n.d.).

The movie was adapted from Marlon Brando starrer On the Waterfront. A sequence in the film shows Aamir Khan running on rail tracks towards an oncoming train, which misses him by a few feet as he jumps off the tracks. 1.3 seconds was the only difference between Aamir and the 
train. This stunt was actually performed, and by Aamir himself. It won him the Best Stunt award, but he later criticized himself for taking such an unnecessary risk.

\section{FINDINGS}

AndazApnaApna seems to have tried to entertain the movie viewers in a vernacular taporilanguage which became a trendsetter for a couple of years amongst cinema goers and movie viewers as the film touched the psyche of vagabond and ponderous youths who spare much of their time doing nothing and discussing on trivial things all the time. On the contrary, the movie appears to have transformed the way of presentation of comedy and chuckling moments. Subsequently, AndazApnaApna happens to be one of the distinguishing comedy films in the history of Hindi Cinema. Thus, this movie may be considered one of the cult classic films of Bollywood.

On the other hand, Raja Hindustani is supposed to have been decorated around a tantalizing screenplay where an affluent girl found her utmost love with greatest intensity but all her dreams go shattered as soon as dividing line between rich and poor sewed and they separated for a short while which ultimately paved way to stitch a warm rapport of love and affection and eternal faith for each other. The movie attempts to focus on the deep chasm of rich and poor when it comes to marry and live a life with dignity and respect in the society. Though, the movie has some shortcomings like a typical clichéd Hindi film love story that is up and down, worthless dialogues, and some idiosyncratic mistakes; but the performances and characters played by Aamir Khan on silver screen in the movie simply oozes catharsis.

Ghulam intends to glorify a lumpen boy who ultimately became a reformer as portrayed on silver screen. Emotional scenes are poignantly performed by Aamir Khan. The movie seems to be a melodrama as the scenes and screen play sometimes fills fervour in actor's veins as his father lived a life full of honesty and integrity till his last breath and ultimately he sowed seeds of reformation to change the prevailing ghettoise unruly and riotous scenario of his entire locality. The narrative, however, elucidates a long, bloody series of fights. The movie also adopts a love angle but this is not merely a lovey-dovey lustful or erotic film. In a word, Ghulam entertains and the exuberant song Aati Kya Khandalastands unmatched. The screenplay, dialogues, direction, storyline, and songs are vehemently awesome and mesmerising.

\section{CONCLUSION}

The twenties saw Aamir Khan's greatest work as producer-director, besides establishing himself as today's biggest film star of Bollywood along with Shahrukh Khan and Salman Khan. Aamir Khan is tremendous, prodigious and terrible actor as is evident after analysing the treatment given to the movies under study. His emotions appear to be more dramatic and exciting than any other actor in the industry. Interestingly, Aamir Khan is not known just for his personality but the remedial aspects intertwined in his movies is unparalleled. The researcher distinguishes, however, negligible criticisms aside, Aamir Khan's movies give a message to its viewers as even his light entertaining comedy film AndazApnaApnahas something to supply to its audience to make them delighted and radiant. Likewise, Raja Hindustani not only hit theatres and went on earning huge moolah at box office, but it seems that the chemistry of love between Aamir Khan and Karisma Kapoor worked tremendously to enliven the tradition of love marriages in the society during 90s in India. The movie is aesthetically shot and appears to have kindled the flame of elegant, delicate and exquisitely beautifulnotions in the society. While, Ghulam tells another story where the lasting effect of his deceased father ultimately compelled Aamir Khan to differentiate between right and wrong and stand firmly against injustice, cruelty and the evil-doers. Aamir Khan did a tremendous job in the movies under study and tried to perform the characters of comedy, romance, reformer and playback singer on silver screen in an equivalent proportion. The idea of stories and execution of the screen play in his movies exactly superb and unforgettable.

\section{SUGGESTIONS}

After having critical analysis of the movies under study, it seems to have established that Aamir Khan mostly attracts audience in serious characters. It is often presumed that Aamir Khan's movies will certainly put different aspects and the treatment of the stories of his every new movie contain message-oriented features, the serious exposure portrayed by him on silver screen will definitely make the spirit and optimism of the audience alive. 


\section{REFERENCES}

[1] Bamzai, K. (2010). Aamir Khan: Mr. Blockbuster. India Today Retrieved from https://web.archive.org/ web/20140226214707/http://indiatoday.intoday.in/story/Aamir\%2BKhan\%3A\%2BMr\%2BBlockbuster/1/ 78177.html (22 April 2019).

[2] Verma, S. (2012). Birthday Special: The 47 Faces of Aamir Khan. Retrieved from https://www.rediff. com/movies/slide-show/slide-show-1-the-47-faces-of-aamir-khan/20120314.htm\#1 (2 April 2019).

[3] Planet Bollywood. (n.d.). AndazApnaApna. Retrieved from http://www.planetbollywood.com/display Review.php?id=032706043445(22 April 2019).

[4] Bollywood Hungama. (1998).Ghulam. Retrieved from https://www.bollywoodhungama.com/movie/ ghulam/ (10 April 2019).

[5] Mukherjee, S. (2017). Raja Hindustani turns 21: Did you know Aamir Khan consumed one litre of vodka for the film?Hindustan Times. Retrieved from https://www.hindustantimes.com/bollywood/rajahindustani-turns-21-did-you-know-aamir-khan-consumed-one-litre-of-vodka-for-the-film/storyQEUGcbz51ZQPJZeG8V35ZL.html (1 May 2019).

[6] Vijayakar, R. (2012). Qayamat se QayamatTak: Turning Point. Retrieved from https://web.archive.org/ web/20140227181023/http://www.bollywoodhungama.com/movies/features/type/view/id/3569/ (22 April 2019).

Citation: Afaq Ahmad. "A Critical Analysis of Bollywood Actor Aamir Khan's Selected Movies". International Journal of Media, Journalism and Mass Communications (IJMJMC), vol 5, no. 2, 2019, pp. 713. doi:http://dx.doi.org/10.20431/2455-0043.0502002

Copyright: (C) 2019 Authors. This is an open-access article distributed under the terms of the Creative Commons Attribution License, which permits unrestricted use, distribution, and reproduction in any medium, provided the original author and source are credited. 